\section{MÁS ALLÁ DE LA REPRESENTACIÓN. ¿ES VISIBLE LA REALIDAD? (IMÁGENES Y CONOCIMIENTO)}

\author{
Josep Maria Català \\ Universidad Autónoma de Barcelona \\ https://orcid.org/0000-0003-4768-916X \\ JosepMaria.Catala@uab.cat
}

\section{BEYOND REPRESENTATION. IS REALITY VISIBLE? (PICTURES AND KNOWLEDGE)}

Cómo citar este artículo/Citation: Català, J. M. (2018). Más allá de la representación. ¿Es visible la realidad? (Imágenes y conocimiento). Arbor, 194 (790): a485. https://doi. org/10.3989/arbor.2018.790n4010
Copyright: (C) 2018 CSIC. Este es un artículo de acceso abierto distribuido bajo los términos de la licencia de uso y distribución Creative Commons Reconocimiento 4.0 Internacional (CC BY 4.0).
RESUMEN: El trabajo de la ciencia con las imágenes nos muestra procedimientos que se alejan, por un lado, de los rigores del estricto método científico, y que crean, por el otro, innumerables paradojas, cuya intensidad se acrecienta a medida que aumenta la complejidad del objeto estudiado. A las operaciones simbólicas y retóricas configuradoras de las imágenes científicas, la mayoría de carácter tecnológico, se añaden los procesos de visualización que ponen en escena, en muy diversos niveles, las relaciones fundamentales de aquellas. Los nuevos estudios sobre la representación científica hablan de imágenes cargadas de teoría que se acercan a la eventualidad de una ciencia poética, cuyo camino habría sido abandonado a partir del siglo XVII, cuando la ciencia moderna provoca la separación epistémica entre lo real y la realidad.

PALABRAS CLAVE: Visión; imaginación; alegoría; fotografía; imágenes técnicas; modelos; tercera cultura; mito; divulgación; representación; arquetipos.
ABSTRACT: The work of science with images shows us procedures that deviate, on the one hand, from the rigors of strict scientific method, and on the other, create innumerable paradoxes, whose intensity increases as the complexity of the object studied grows. To the symbolic and rhetorical operations that constitute the scientific images, most of which are technologically created, one must add the process of visualization that has staged, at very different levels, its underlying relationships. New studies on scientific representation point to the existence of theory loaded images that approximate the possibility of a poetic science. This path was abandoned in the seventeenth century, when modern science generated an epistemic gap between the real and reality.

KEYWORDS: Vision; imagination; allegory; photography; technical images; models; third culture; myth; divulgation; representation; archetypes. 
La imaginación nunca despunta

Si no es sobre el estímulo

De un indispensable límite

Pere Ballart

Deleuze iniciaba sus clases sobre Foucault afirmando que el pensamiento de este giraba en gran medida en torno al "ver". ¿Qué significa ver? Según Deleuze, para Foucault, ver y decir eran formas del saber: "Qué se dice en una época, qué se ve en una época [...] Un régimen de 'decir' es la condición de todas las ideas de una época. Un régimen de 'ver' es la condición de todo lo que hace una época" (Deleuze, 2013, p. 16). Sin embargo, rara vez se detiene Foucault en una imagen concreta. Si acaso al principio de Las palabras y las cosas describe con finura Las Meninas de Velázquez, a lo que hay que añadir la monografía sobre Esto no es una pipa de Magritte y un escrito póstumo que aborda la pintura de Manet. Pero no parece que, en ningún caso, "ver" esté relacionado directamente con lo visual, ni con las imágenes. Para él, "ver" es más una forma de organizar el mundo visible que permanece, no obstante, en la abstracción, sin casi nunca ceñirse a un acto de visión específico, más allá de algunas referencias como las que hace, por ejemplo, al Panóptico de Bentham en Vigilar y castigar, o la consiguiente relación que establece entre la arquitectura y las formas de la visión. Esta exclusión de la imagen en sí misma es muy significativa y está relacionada directamente con el proverbial rechazo del ocularcentrismo que, según Martin Jay, caracteriza al pensamiento francés moderno:

El progresivo, aunque uniformemente aceptado, desenmarañamiento de lo figurativo respecto de su tarea textual -la desnarrativización de lo ocular, podríamos llamarlo- fue un elemento importante de esa transformación generalizada por la que se pasó de leer el mundo como un texto inteligible (el "libro de la naturaleza") a mirarlo como un objeto observable pero carente de significado, que Foucault y otros han considerado el emblema del orden moderno. Solo con esta transformación epocal pudo darse la "mecanización de la imagen del mundo", tan esencial para la ciencia moderna (Jay, 2007, p. 46).

El caso de Foucault nos ayuda a situar, pues, la cuestión de la imagen científica en el lugar adecuado, ya que parece que con el proceso de desnarrativización del que habla Jay se desvanece también la imagen en sí misma, aquella que es capaz de organizar visualmente el "ver". Y eso ocurre justo para dejar el camino libre a la ciencia moderna, la cual ha estado relacionada, sin embargo, con las imágenes desde un principio, si bien de manera bastante ambigua.

Se pregunta Deleuze si las ideas sobre el "ver" de Foucault implican "una concepción suya sobre la pintura, una concepción en la que la luz es condición de la pintura, condición del acto de pintar" (2013, p. 21). Y su respuesta es que habrá que preguntárselo al autor. Pero el autor no responde en el sentido en que a nosotros nos interesa, que tiene que ver más con la fenomenología de la imagen que con las "condiciones de los comportamientos históricos y de las mentalidades históricas" (2013, p. 16). En todo caso, se trata de señalar el camino para poder detectar en las propias imágenes el rastro de esas condiciones. $\mathrm{O}$, para decirlo llanamente, se trata de poner a Foucault cabeza abajo.

¿Se pueden pensar las imágenes como una historia del ver? Efectivamente, es posible hacerlo, pero solo si incluimos en esta historia las imágenes científicas, que apenas si están presentes en la historia del arte, a no ser de manera indirecta. Hasta ahora, la imagen había configurado una historia de la representación, un régimen que en el siglo XVII vino a sustituir al de la semejanza, tal como lo expuso Foucault. Pero la imagen científica nos sitúa ahora más allá de la representación, nos conduce al ámbito de la presentación.

Aun cuando las imágenes entendidas como representación nos informan principalmente de la mirada del autor, hay inscrita en ellas no solo esa mirada social de la que trata Foucault, sino también la mirada individual del espectador de las mismas, que mira $a$ través de la configuración visual. Ver es poner en contacto el mundo con la imaginación por medio de un proceso simbolizador. Este proceso, que se proyecta tanto sobre el mundo como sobre la imaginación, se hace por medio de la imagen, de estructuras visuales, de lo que la imagen organiza, así como de la propia organización de la imagen. En una posible historia del ver, establecida según estos parámetros generales, la imagen científica es crucial, porque se desarrolla en las trincheras de la epistemología, allí donde se libran crudamente aquellas batallas que luego el resto de las imágenes representan.

A la prototípica ambigüedad epistemológica de la imagen científica se le añade una ambigüedad genérica no menos importante. ¿Cuál es el campo que abarca la imagen científica? ¿Hablamos solo de las imágenes experimentales, que supuestamente reproducen la realidad, aunque sea a través de ins- 
trumentos tecnológicos? ¿o incluimos asimismo las descripciones visuales, que tan gran importancia tuvieron en los inicios de la ciencia moderna? ¿Nos deben interesar también los modelos y los experimentos mentales, de los que tantos ejemplos hay en la historia de la ciencia, desde la manzana de Newton hasta los ascensores y los trenes de Einstein o el gato de Schrödinger? ¿Qué papel desempeñan los diagramas, como los que proponía Feynman, o la visualización de los datos que ahora se ha dado en llamar big data? En resumidas cuentas, ¿dónde se encuentran exactamente los límites de la imagen científica? Recordemos que escritores como Zola pretendían escribir novelas experimentales y que, para George Eliot, su obra era un conjunto de experimentos sobre la vida, en la estela ambos de las ideas del fisiólogo Claude Bernard en su Introducción al estudio de la medicina experimental. Por otro lado, ¿dónde situar las imágenes que provienen de la divulgación científica? ¿y en qué punto empieza y termina exactamente esta? ¿No existe una correlación muy estricta entre las visualizaciones que se producen, por ejemplo, en el terreno de la ciencia-ficción, tanto literaria como cinematográfica, y las ideas científicas de una época? Son demasiadas preguntas como para intentar responderlas en un artículo. Trataré simplemente de exponer los distintos aspectos del problema de la relación entre la imagen, la realidad y el conocimiento a través de un paseo por el bosque que configuran las imágenes científicas, que son las mejor situadas para dilucidarlo.

\section{NOSTALGIA DE LA LUZ}

Para hablar de un objeto tan misterioso, o quizá podríamos decir tan complejo, como la imagen científica, vale la pena empezar por una idea, no menos enigmática, que Barthes expresa en su conocido estudio sobre la fotografía. Esta idea la desarrolla el autor por medio de tres movimientos conceptuales. En el primero relaciona la foto con el referente, poniendo de relieve la condición táctil del fenómeno: "La foto es literalmente una emanación del referente. De un cuerpo real, que se encontraba allí, han salido unas radiaciones que vienen a impresionarme a mí, que me encuentro aquí" (Barthes, 1997, p. 142). Esta sensorialidad se produce por medio de un recorrido espacial (allí, aquí) cuya textura es sin embargo temporal, puesto que la distancia que separa el allí del aquí implica sobre todo un desplazamiento en el tiempo al que Barthes no parece atender demasiado: "Importa poco -añade- el tiempo que dura la transmisión" (1997, p. 142).
Lo cierto es que la relevancia de esta duración, cuya tesis supone el segundo movimiento conceptual de la idea de Barthes, es bastante mayor que la que le concede el filósofo. Una fotografía conserva su vigencia porque proviene del pasado. Tal temporalidad acarreada le otorga una eficacia perenne. Se trata de un aliento que se resiste a desaparecer y que sirve de antídoto a una previsible desactivación de la foto, ocasionada precisamente por el paso del tiempo, cuyo transcurso debería convertirla en obsoleta como a cualquier otro objeto sujeto al régimen de la modernidad. Sin embargo, las fotografías parecen escapar a dicho imperativo, y cada vez que contemplamos una de ellas, por antigua que sea, se activa el dispositivo espacio-temporal que une el allí de entonces con el aquí de ahora; se pone en marcha una especie de máquina del tiempo que permite que me llegue una emanación, que me alcancen unas radiaciones cuyo impulso se inició antaño. Es el anterior un envite que quedó recogido en la imagen fotográfica de la misma forma en que el potencial de una planta hiberna en sus semillas. Es ahora, al mirar la fotografía, cuando los elementos dormidos despiertan y me alcanzan.

Finalmente, he aquí el tercer movimiento, quizá el más trascendental puesto que amplía drásticamente el concepto de lo fotográfico: "La foto del ser desaparecido viene a impresionarme al igual que los rayos diferidos de una estrella. Una especie de cordón umbilical une el cuerpo de la cosa fotografiada a mi mirada: la luz, aunque impalpable, es aquí un medio carnal, una piel que comparto con aquel o aquella que han sido fotografiados" (Barthes, 1997, p. 143).

Barthes pone así los cimientos de una potente mitología que sin duda incomodaría a la ciencia, si esta accediera a pensar en la línea en que lo hace el filósofo. Sin embargo, la apuesta ya está hecha y resulta difícil rechazarla. Lo más relevante de la misma reside en la comparación que Barthes realiza entre una foto y "los rayos diferidos de una estrella". Esta apelación a la astronomía sitúa el problema donde le corresponde a un medio técnico como el fotográfico y, a la vez, obliga a darle la vuelta a la metáfora de Barthes, de manera que en lugar de hacer como él y comparar la fotografía con una estrella hemos de pasar a comparar una estrella con la fotografía.

\section{LA AMENAZA DE ANDRÓMEDA}

Contemplo la fotografía de la galaxia de Andrómeda, un cuerpo celeste situado a dos millones y medio de años luz de nuestro planeta, y me pregunto si estoy realmente viendo esa galaxia, aunque sea a 
través de una imagen de la misma. Se diría que sí, puesto que la técnica fotográfica posee la virtud de reproducir aquello que tiene ante el objetivo. Pero me asalta la duda de pensar si realmente la galaxia ha estado alguna vez delante del objetivo de la cámara que captó esa fotografía que yo estoy viendo. Lo cierto es que si dejo a un lado la foto y miro directamente al cielo estrellado, la citada galaxia apenas aparecerá como un punto de luz no muy distinto del de otras estrellas más o menos brillantes que hay a su alrededor. Para obtener la fotografía de la galaxia que estoy contemplando, y en la que esta figura en todo su esplendor como si se hallara literalmente al alcance de la mano, el objetivo de la cámara, que siguiendo a McLuhan podría considerarse una extensión del ojo, ha tenido que ser acoplado a un telescopio, que es algo más que un remedo de la vista. Lo que contemplo, pues, en la fotografía es aquello que Flusser denominaba una imagen técnica, que me ofrece una vista muy peculiar de la galaxia: este tipo de imágenes han sido confeccionadas por aparatos diseñados de acuerdo con determinadas teorías, y son por lo tanto, dice Flusser remedando a Platón, imágenes de tercer grado: "Provienen de textos que provienen de imágenes tradicionales que a su vez provienen del mundo concreto" (Flusser, 2006, p. 14). Puedo decir, consecuentemente, que al contemplar la imagen de la galaxia estoy viendo ese cuerpo celeste según determinada concepción del mundo o, como afirma el propio Flusser de manera más drástica, "en el caso de las imágenes técnicas, nos encontramos frente a productos indirectos de los textos científicos" (2006, p. 14).

Esto que está expresado de forma tan sencilla por Flusser no solo determina la condición de las imágenes técnicas, sino también la de las imágenes científicas en general, incluso si ambas no son exactamente lo mismo. No todas las imágenes técnicas son científicas, ni todas las científicas son estrictamente técnicas. En el campo del arte, por ejemplo, se producen actualmente innumerables imágenes técnicas que, sin embargo, no pueden considerarse científicas, y la ciencia promueve muchas imágenes, como los diagramas o los dibujos, que no son técnicas en un sentido estricto, es decir, engendradas por un aparato, aunque expresen una teoría, y por lo tanto sean equiparables en ello a las imágenes técnicas.

En realidad, cualquier imagen tiene como fundamento una concepción del mundo y expresa, más concretamente, alguna teoría sobre la visión y la representación, como sucede, por ejemplo, con las relaciones entre la pintura y la técnica de la perspectiva. Pero la diferencia con las imágenes científicas reside en que estas, además de esos otros sustratos, que en ellas se sitúan en un segundo término, visualizan, explícita y directamente, determinada teoría, algo que las imágenes técnicas hacen de manera automática. Existe, pues, un subconsciente de las imágenes científicas que organiza las estructuras fundamentales desde las que se despliega el trabajo teórico formulado a su vez mediante la función expresa de la imagen. En las imágenes técnicas tal subconsciente está materializado por la propia tecnología. Podría decirse que, al manejar un aparato, llevamos el inconsciente social a cuestas, una parte del imaginario convertido en ingeniería. En las imágenes científicas que no son técnicas, el peso de ese inconsciente puede ser igualmente importante, puesto que las mentalidades las forman también los aparatos no solo por su uso, sino por la estructura epistemológica que despliegan.

La imagen científica no se distingue demasiado de la imagen artística, excepto porque en aquella la voluntad de referirse al mundo real manifiesta un factor activo que contrasta con la actitud pasiva de esta última. ¿Cabría decir, en líneas generales, que la imagen artística representa, mientras que la científica, incluida la imagen técnica, visualiza? La diferencia podría establecerse entre un procedimiento metafórico y otro alegórico. La representación artística implica una transformación formal del referente, mientras que por medio de la visualización científica los referentes se muestran o bien de modo pretendidamente literal o por medio de relaciones, y en ninguno de los dos casos la transformación formal tiene en sí misma relevancia. La transformación metafórica que una taza y un plato experimentan, por ejemplo, en un cuadro de Zurbarán reside estrictamente en la forma, mientras que en el modelo atómico de Niels Bohr, que muestra el átomo como un pequeño sistema planetario, las características formales a través de las que se representan los electrones o el sistema no son inmediatamente relevantes. Poco importa si los electrones son de color amarillo o rojo, o si las órbitas tienen un mayor o menor grosor. La trascendencia reside en la estructura del modelo, la cual resulta como si estuviera situada más allá del mundo físico. En palabras de Heisenberg, acérrimo detractor de la visualización en la física, "el movimiento de los electrones no puede describirse en términos de los tradicionales conceptos de espacio y tiempo" (Miller, 1987, p. 142), una afirmación de mucho mayor calado de lo que en un principio parecería. 
Podemos decir, pues, que tanto la imagen de los electrones a modo de pequeños planetas como su comportamiento circular son un vehículo visual para expresar lo que se antoja inexpresable en ese nivel. Tal proceso de hacer inteligible algo que en principio se considera invisible se realiza de dos maneras posibles: recurriendo a la metáfora o a la alegoría. Si damos forma, a través de parámetros físicos conocidos, a estructuras que consideramos inconcebibles de otra manera, estamos utilizando la metáfora. Por el contrario, si recurrimos a las matemáticas sin más, tenderemos la alegoría, a pesar de que la tradición científica insista, desde Galileo, en que no se está expresando matemáticamente el mundo, sino exponiendo las matemáticas de las que está hecho el mundo. Si esto fuera así, nos encontraríamos ante una genuina alegoría platónica por la que el mundo real visible representa las verdaderas ideas matemáticas, y no a la inversa.

La auténtica alegoría de la imagen científica adopta, sin embargo, otra forma, y absorbe en su seno cualquier operación metafórica, que queda subsumida en un rango retórico en este caso de carácter superior. La alegoría, como es sabido, designa el procedimiento por el que las ideas se convierten en cosas, se representan a través de ellas. Las características estéticas de estas cosas no modifican, se piensa, la identidad de las ideas originales. La estética solo entra en juego en el caso de que se establezca una nueva codificación que otorgue un significado concreto a cada una de las modificaciones, en cuyo caso no hacemos sino extender un poco más el régimen de la alegoría. En una imagen científica, la visualización alegórica es más significativa que la representación metafórica, aunque ambas configuraciones pueden aparecer superpuestas en un mismo proceso.

\section{LO VISIBLE Y LO INVISIBLE}

El mundo, por tanto, parece haberse escindido, desde los inicios de la ciencia moderna, entre el ver y el saber. Y da la impresión de que ambas esferas son irreconciliables, a pesar de que la observación visual está en las raíces del procedimiento en la ciencia. Es así como la visualización científica se ha ido convirtiendo en alegórica, alcanzando a la visión hiperbólicamente, por la puerta de atrás. El saber diluye lo visible, los fenómenos, en sus componentes fundamentales de carácter matemático y abstracto, pero a continuación procede a visualizar estos parámetros con distintas finalidades. En primer lugar, para poder manipular la realidad a partir de esas visualizaciones, ya sea directamente, como mediante las imágenes digitalizadas, o mentalmente, a través de los conocidos modelos o experimentos mentales. $Y$ en segundo lugar, para divulgar las ideas científicas. La alegoría se produce igualmente en ambos casos, pero en este último crea lo que podríamos denominar un sistema mitológico, la plasmación narrativa y didáctica de un mundo abstracto. Si bien desde la perspectiva estrictamente científica los primeros procedimientos son siempre los más relevantes, desde la vertiente humanista el énfasis recae en la segunda posibilidad. Tengamos sin embargo en cuenta que, excepto en aquellos casos extremos más ligados a la tecnociencia en que la matematización del pensamiento es total, ambos grupos de imágenes funcionan similarmente como un soporte para la imaginación destinado a auxiliar al pensamiento.

Existe otro tipo de imágenes, al que pertenece la fotografía de la galaxia de Andrómeda de la que estamos hablando: son las imágenes técnicas que nos muestran supuestamente una visión directa de la realidad. Estas imágenes pretenden abarcar desde la parte más alejada del cosmos hasta las regiones subatómicas. Se trata de visualizaciones que presentan problemas particulares, relativos la mayoría de ellos a la actuación tecno-retórica ejecutada sobre la imagen técnica, tanto a priori como a posteriori. Es necesario recalcar que el fundamento del despliegue retórico de las imágenes científico-técnicas es de carácter tecnológico. Dicho de otra manera, su condición retórica no es solo interpretativa, sino que se asienta sobre determinados dispositivos tecnológicos. En este sentido, un telescopio y una metáfora pueden llegar a ser equivalentes.

Pese a todo ello, es decir a este entramado retórico y tecnológico que se interpone entre el referente y la imagen, un astrónomo considerará que una fotografía de la galaxia de Andrómeda como la que contemplo constituye una perfecta visualización del objeto celeste correspondiente. En eso coincidirá curiosamente con cualquier lego en la materia, aunque el fundamento de sus creencias tenga un origen muy distinto. Si tomamos en consideración las diversas controversias que se han producido en la historia de la ciencia acerca de la visualización de la realidad, empezando no solo por Galileo sino por Platón, su claro antecedente en cuanto a la desconfianza hacia las imágenes, coincidiremos en que el concepto mismo de visualización es ciertamente problemático:

Al igual que "representación", "visualización" es un término cargado, como lo son los conceptos relacionados de "observación" y de "percepción". Quizá la mejor manera de usar estos términos no sea, pues, a 
modo de resumen descriptivo, supuestamente neutral, del trabajo científico, técnico o médico que es objeto del análisis, sino como conceptos inestables: ¿es con una representación con lo que estamos tratando? ¿Aquello con lo que estamos tratando nos lleva a extender, o expandir, o a repensar lo que queremos decir con este término? ¿Podríamos, por ejemplo, siguiendo la provocativa sugerencia de Rheinberger, concebir la "actividad de la representación científica $[. .$.$] como un proceso sin referente y sin origen"?$ (Coopmans, Vertesi, Lynch y Woolgar, 2014, p. 4).

Se diría que considerar la imagen científica como un proceso sin referente ni origen la situaría en el ámbito del simulacro, al modo de Baudrillard. Si pensamos en el uso de los modelos en la ciencia y los relacionamos con los modelos mentales que subyacen en su dramaturgia, veremos que la falta de una referencialidad estricta no es demasiado extraña. Sin embargo, Rheinberger parece concebir la actividad científica como un proceso, es decir no en cuanto producto terminado, imagen fija o modelo estático, sino en tanto que transcurso, cuya característica fundamental es el movimiento.

Aquí nos encontramos inmersos, de pronto, en otro paradigma que se superpone fácilmente al más tradicional. A pesar de que llevamos más de un siglo con imágenes en movimiento, aún pensamos esencialmente a través de imágenes fijas. Sucede así porque propendemos a valorar en mayor medida las esencias que los acontecimientos. Es por ello también por lo que el científico tiende a desconfiar de los fenómenos. Sin embargo el movimiento resulta esencial para el conocimiento, puesto que es la mejor manera no solo de expresar el pensamiento a través de las formas audiovisuales, sino también de reflexionar por medio de tales formas. En ese sentido, el proceso científico sería equiparable a la forma ensayo, especialmente al ensayo audiovisual. Pero si bien esto podría explicar muchas cosas, seguramente no sería del agrado no tanto de los propios científicos como de aquellos que defienden a ultranza un método científico del cual hay muchas razones para dudar que sea como su visión idealista lleva a creer.

Recordemos, de pasada, la conocida polémica de Alan Sokal que, en el ámbito de la denominada "guerra de las ciencias", iba encaminada a desprestigiar a autores posestructuralistas como Foucault o Lacan, entre muchos otros, por utilizar metafóricamente conceptos científicos de una manera no muy distinta a como vemos que los emplean los propios científicos cuando se apoyan en las imágenes. Sokal y compañía personifican el repliegue de las ciencias sobre sí mismas, frente a la expansión de la cultura científica hacia una tercera cultura que combine las mentalidades científica y humanista, no como una suma ponderada de las dos, sino como una hibridación de ambas que dé paso a una nueva mentalidad. Esa nueva razón se adecuará además a la necesaria mitología que ya desarrollan las actividades divulgadoras, pero ahora en cuanto a un proceder tan esencial para la futura ciencia humanista, la tercera cultura, como lo son las imágenes científicas para la tecnociencia actual.

\section{ALEGORÍAS DE LO REAL}

Entre las diversas mediaciones que ha experimentado la imagen de la galaxia de Andrómeda antes de llegar a mis manos no es la menor el hecho de que ha sido convenientemente coloreada, a través de una serie de procesos que nos reafirman en la convicción de que el color aplicado no es en este caso metafórico, sino alegórico. Precisamente fue Galileo uno de los primeros en manifestar su desconfianza ante ciertas propiedades de los objetos físicos que, como los colores, dependen del sujeto o, según especificaba el propio Galileo, del cuerpo. En su famoso II Saggiatore de 1623 "dejaba claro por qué las imágenes nunca iban a ser útiles, como tampoco lo sería ninguna descripción que dependiera de los sentidos, todos ellos excesivamente subjetivos. Solo aquellas cualidades que se basan en las propiedades objetivas y matemáticamente caracterizables de masa, espacio, extensión y número pueden ayudar a definir lo que es esencial en las cosas de la naturaleza" (Freedberg, 2002, p. 350).

Sin embargo, como nos informa Janet Vertesi, la coloración de las imágenes técnicas se ha convertido en una práctica habitual de lo que podríamos denominar post-observación. Así, las imágenes digitales del planeta Marte suministradas por las sondas espaciales allí enviadas "se transforman en gráficos y luego en colores falsos (false colors) [...] con el fin de desvelar fenómenos que de otra forma serían invisibles, cambiando entonces una observación en visión colectiva que, finalmente, concluya en un descubrimiento adjudicable a la misión" (Vertesi, 2014, p. 16). Este tipo de prácticas de visualización científica se engloban bajo el concepto de "dibujar como": "La representación en la práctica científica es siempre una cuestión de dibujar un objeto natural como un objeto analítico" (Vertesi, 2014, p. 18). Es significativo que, al cabo del camino, la imagen científica recupere, en el marco de la imagen digital, prácticas como el dibujo, que co- 
rresponden a las más antiguas formas de la imagen científica. El concepto de dibujar vale aquí tanto para las primeras imágenes científicas que trataban de reproducir fidedignamente el mundo natural como para las imágenes digitales de la actualidad, en las que la manipulación de la imagen se realiza para "poder ver cosas nuevas" o para "hacer que un elemento escondido aparezca" (2014, p. 25). Existe una diferencia, sin embargo: los procesos de coloración empleados por los dibujantes y pintores de los orígenes de la observación científica eran claramente metafóricos, puesto que tenían un valor eminentemente estético a pesar de su voluntad descriptiva, convenientemente criticada en muchos casos desde la perspectiva de una estricta visión científica, mientras que ahora las coloraciones son alegóricas, ya que responden a lo que se denomina "observaciones cargadas de teoría" (Vertesi, 2014, p. 17). Son colores que expresan ideas sobre, por ejemplo, la composición del suelo.

Cuenta el periodista David Fauquemberg que, durante su recorrido por la llamada "Bible Belt" de los Estados Unidos, vio en una iglesia baptista de Tennessee el siguiente letrero: "Vision is the art of seeing invisible things" (la visión es el arte de ver cosas invisibles) (Sonda, 2010, p. 2). Atendiendo a Sonda, los científicos tienen ante la visualización la misma actitud que los religiosos: ambos consideran los dispositivos visuales como un medio de demostrar la verdad. Sin embargo, la verdad no se demuestra solo señalándola, como parece querer hacer la imagen científica, sino a través de una determinada argumentación retórica. Latour afirma que "las ciencias no hablan del mundo sino que más bien construyen representaciones que parecen alejarlo siempre, aunque también lo aproximan hasta un primer plano" (2010, p. 44). Estos procesos combinados de alejamiento y acercamiento ponen de manifiesto formas reflexivas que corroboran el carácter de simulacro de la imagen científica, es decir de construcción hermenéutica. Las cosas invisibles se harían así visibles mediante una puesta en visión que implica un proceso reflexivo.

La pregunta que podríamos hacernos ahora, si siguiéramos una vieja costumbre que hoy ha quedado prácticamente obsoleta, sería cuál es la verdadera imagen de la galaxia de la que estamos hablando. Es más, cabría cuestionar si existe una verdadera imagen de la misma. Una cosa es lo que veo con el ojo desnudo y otra lo que aparece si miro a través de un instrumento óptico, y otra más lo que se muestra en la fotografía. La imagen que hay en esta es algo que nun- ca podría ser visto directamente, aun cuando lográramos viajar lo suficientemente lejos para acercarnos a los alrededores de la galaxia, de manera que pareciera que esta se halla al alcance de la mano. Si tal aproximación fuese posible, el objeto dejaría de asemejarse a un todo homogéneo de forma espiral, puesto que se disolvería en el conjunto de elementos que lo componen, igual que sucede con la vía láctea, nuestra galaxia particular.

Me estoy refiriendo obviamente a una región de la realidad que tiene que ver con la visión humana, pero hace tiempo que la ciencia ha descartado ese ámbito, ha dejado de considerarlo primordial. Según Freedberg, fue en el siglo XVII cuando empezó el declive de las imágenes tradicionales en la ciencia y se inició la era de los diagramas: "La descripción gráfica de la superficie de las cosas no mostraba los principios del orden; estos solo podían ser alcanzados penetrando por debajo de la superficie, contando y reduciendo la globalidad de la descripción visual a sus esenciales abstracciones geométricas" (2002, p. 4).

En el campo de los modelos científicos, la pregunta de cómo se relacionan estos con el mundo ha recibido numerosas y contradictorias respuestas. Desde la denominada visión sintáctica, "según la cual los problemas de la representación científica son contemplados como un caso especial de un problema más general: la relación del lenguaje con la realidad" (Frigg y Hunter, 2010, p. xvii), hasta la visión semántica, que contempla las teorías científicas como "una colección de modelos más que de frases, en la que los modelos están construidos como entidades no lingüísticas", la representación científica deja de lado el mundo visible para concentrarse en la forma de los propios modelos: "Las estructuras así entendidas no son en sí mismas 'sobre' nada del mundo" (2010, p. xviii). Es por ello por lo que Ronald Giere puede pretender que los modelos resultan como objetos idealizados.

Peter Galison analiza las teorías a propósito de la física de partículas desarrolladas en el siglo XX como una lucha entre dos tradiciones enfrentadas: "De un lado se encuentra la 'tradición de la imagen', o esas teorías e instrumentos experimentales diseñados para producir representaciones que son 'presentadas y defendidas' en tanto miméticas: pretenden preservar la forma de las cosas tal como ocurren en el mundo. Mientras, la tradición opuesta, 'lógica', se organiza alrededor de teorías e instrumentos ingeniados para producir datos estadísticos, constituyendo lo que Galison denomina 'representación homóloga'” (Frigg y Hunter, 2010, p. xxiv). 
Pero, como indican Frigg y Hunter, "ni la visión fuertemente mimética ni la rigurosa visión convencionalista pueden dar cuenta satisfactoriamente del complejo y variopinto campo de las representaciones científicas estudiadas actualmente por los filósofos de la ciencia" (2010, p. xx). En ninguno de los casos citados se da importancia al mundo humano, aquel en el que vivimos, reemplazado por una estructura operativa del mismo, que en el caso de que sea convencional se aleja excesivamente del sentido común, y que si es mimética restringe en exceso los límites de este sentido. De ahí precisamente que algunos científicos como Heisenberg rechazaran la tradición visualista, si bien lo hicieron para caer en la más pura abstracción, en un territorio controlable pero que es terreno de nadie.

\section{LÍMITES DE LO VISIBLE}

El fenómeno de la contemplación de la fotografía de la galaxia de Andrómeda aún presenta algunas asperezas que deben ser limadas antes de seguir adelante. Se trata de lo referido al tiempo y la luz, aquello que constituye la base de la mitología de Barthes antes mencionada. Siguiendo a Barthes la fotografía constata que lo que vemos "ha sido", ha estado allí alguna vez. ¿Podemos decir lo mismo de la galaxia, en el sentido histórico que el teórico le confiere a esa distancia que la fotografía mantiene con sus espectadores? Para él, "la historia es histérica: solo se constituye si se la mira, y para mirarla es necesario estar excluido de ella" (1997, p. 118). Esta afirmación nos recuerda la idea de Latour respecto de las representaciones científicas, la cuales, según el autor, alejan a la vez que acercan. ¿Es la galaxia historia de hace dos millones y medio de años? En todo caso, no lo es en el sentido que le atribuye Barthes a la historia transmitida por la fotografía, puesto que en ella la imagen deja constancia de algo que ha sido, pero que ya no es. La imagen del pasado llega aquí a través de un proceso de hibernación para despertar ante nosotros, pero la idea que tenemos del universo nos indica que la galaxia está allí, sigue estando allí, ahora, cuando nos alcanza la luz que inició su camino hace dos millones y medio de años.

Hay una escena en la excelente película de Robert Zemeckis Contacto (1997) que visualiza una inusitada percepción del cosmos capaz de incidir directamente en esta paradójica composición que estamos planteando. El personaje interpretado por Jodie Foster arriba al final de un incierto viaje cósmico para el que se ha estado preparando durante mucho tiempo, desciende del vehículo que lo ha transportado y se enfrenta a un paisaje desconocido en cuyo cielo apa- recen enormes objetos, entre ellos una galaxia espiral que da la impresión de estar tan cercana como la que nos puede mostrar una fotografía astronómica. Foster levanta la mano para protegerse los ojos de la intensa luminosidad que arroja el conglomerado de estrellas y desapercibidamente roza lo que semeja una superficie líquida que se halla sobre su cabeza y sobre la que se proyecta la espectacular imagen de la galaxia entre otros resplandecientes astros. Se dan a ver aquí, en este planteamiento ficticio, dos teorías aparentemente contrapuestas: la mitología fotográfica de Barthes, según la cual la imagen fotográfica establece la continuidad de una piel que conecta el presente con el pasado, y las últimas ideas sobre la posibilidad de que nuestro universo sea un holograma. Siguiendo esta hipótesis, desplegada en el número de diciembre de 2013 de la revista Nature, "el universo podría consistir en una gran proyección, de modo que las tres dimensiones que percibimos estarían realmente 'pintadas' sobre el horizonte cosmológico, los límites del universo conocido". Comentando las ideas del físico David Bohm, Michael Talbot indica que este "iba paulatinamente desarrollando una imagen de la realidad en la que las partículas subatómicas no estaban separadas unas de otras y se movían a través de un vacío espacial, sino que en su concepción todas las cosas formaban parte de una red global y se hallaban embebidas en un espacio que era tan real y se encontraba tan lleno de procesos como la materia que se movía en su seno" (Talbot, 1992, p. 43).

Hemos llegado a un punto en el que la divulgación científica, que proyecta sobre el mundo visible la elaboración imaginaria extraída por el propio científico de sus teorías abstractas, confluye con la ficción, especialmente con la denominada ficción científica, y muy concretamente con la cinematográfica. La divulgación, gracias a las ilustraciones y a otros medios didácticos, se encarga de extrapolar las ideas científicas al mundo visible, amoldándolo a las regulaciones de las mismas para que, a través de sus procesos de visualización, las teorías puedan ser culturalmente comprendidas. Cuando se insta a que la ciencia forme parte de la cultura general se está abogando por este tipo de operaciones, cuyo valor, sin embargo, se halla siempre bajo sospecha desde la perspectiva de la propia cultura científica. Afirma Moser, hablando de cómo las ideas son visualmente representadas en la arqueología, que "es en las ilustraciones donde se plantean los argumentos acerca de lo que constituye la humanidad [...] La razón de mostrar ilustraciones es hacer que un argumento sea más visible y así más creíble" (Moser, 1996, pp. 185-187). 
Por su parte, la ficción establece hipótesis, a veces fantasiosas, otras mejor fundamentadas, a partir del clima cultural creado por la ciencia. Desde Julio Verne a Steven Spielberg, quien para realizar su película Minority Report (2002) convocó a numerosos científicos con el fin de que le informaran sobre las perspectivas del cambio social en un futuro próximo, la ficción especula sobre el desarrollo posible de lo científicamente conocido. En ocasiones la figura del científico, la del divulgador y la del autor de ciencia-ficción coinciden, de manera que las tres funciones se entremezclan y dan como resultado operaciones híbridas en las que las fronteras entre los niveles epistemológicos no están muy claras. Un caso notable es el del astrónomo Fred Hoyle aunque, desde una perspectiva menos clásica, destaca por sus heterodoxos planteamientos el matemático Vernor Vige, ganador del prestigioso premio Hugo de novela de ciencia-ficción, quien desarrolla la teoría de la singularidad tecnológica de acuerdo con la cual esta singularidad pone en entredicho la misma cuestión de ver "de la misma manera que lo hace un agujero negro, ya que ambos son puntos de ceguera donde el aparato conceptual humano -dependiendo, por lo menos metafóricamente, de la luz, la vista y la visión- no puede penetrar" (Milburn, 2008, p. 2). He aquí una muestra de lo efectiva que puede ser la novela a la hora de ampliar el argumento de los planteamientos científicos.

Todo ello conforma la mitología de la que hablaba antes y que es la que, en última instancia, construye la visión humana del mundo en que vivimos. Los poderosos efectos especiales del cine actual coinciden, en su proceder y muchas veces en su iconografía, tanto con las manipulaciones científicas de las imágenes que nos llegan del sistema solar a través de las sondas espaciales -compárense las imágenes de los planetas de una gran superproducción fílmica de ciencia-ficción y las que suministra la NASA- como con las visualizaciones de objetos o procesos más imaginables que visibles, como ocurre, por ejemplo, con las procedentes de la nanotecnología.

Existe una red indetectada que conecta la investigación científica, la divulgación y la ficción, por la que circula y a través de la que se forma el verdadero conocimiento no especializado, aquel que da significado al mundo.

\section{LA INSOPORTABLE LEVEDAD DEL SER}

Sabemos que la concepción científica de la realidad cósmica se basa en un postulado muy simple, instaurado por Einstein hace ahora poco más de un siglo: el he- cho de que la luz viaja a trescientos mil kilómetros por segundo y de que esta velocidad es constante e insuperable. Si algún día se demostrara que tal pretensión es incorrecta, al igual que tantas veces ha sucedido en el pasado con otras leyes consideradas absolutas, la arquitectura del cosmos tal como lo concebimos se desplomaría cual castillo de naipes. Se pondría de manifiesto entonces la fábrica barroca del cosmos actual, que ya se revela en conceptos como las supercuerdas, las branas, los agujeros negros o los universos paralelos, pero cuya estructura sigue siendo visualmente concebida de acuerdo con el neoclásico universo newtoniano. El cine de ciencia-ficción actual, denominado posmoderno, se ha encargado de manifestar parejo barroquismo por medio del planteamiento de realidades múltiples, de paradojas temporales o de paisajes que combinan lo objetivo y lo subjetivo. Un ejemplo de especial relevancia es el filme de Christopher Nolan Interestelar (2014), donde se barajan ideas y consecuencias de la nueva cosmología y de la mecánica cuántica de manera emocionalmente asimilable.

La fotografía del cosmos presenta diferencias y similitudes con la fotografía cotidiana. Esta, indica Barthes según hemos comprobado, establece un cordón umbilical con el pasado por medio de la luz, que actúa, dice el filósofo, como una piel compartida con el lejano referente. El pasado no existe, es historia que se activa en el presente, precisamente porque alguien lo contempla. La luz no nos llega como la de una estrella, a través de un espacio inimaginable pero supuestamente real, sino que ha sido almacenada en la fotografía que ahora se encarga de reactivarla para nosotros, después de una elipsis indeterminada. La fotografía se halla, pues, entre el pasado y el presente, es una interfaz entre los dos mundos. Ahora bien, si es capaz de comunicarlos uno con otro, ello de debe a que ha estado viajando hacia nosotros desde el momento en que fue hecha. En este último sentido, la fotografía sí resulta, en efecto, como la luz de una estrella: es una estrella.

Con una salvedad, la de que la estrella sigue supuestamente emitiendo luz, y de que por lo tanto el cordón umbilical lumínico del que hablaba metafóricamente Barthes se hace realidad: hay un haz continuo de luz que conecta mi ojo con el lejano astro. En la fotografía la historia viene hacia mí, mientras que en la visión astronómica yo voy hacia la historia, hacia el pasado, el cual de todas formas toca mi pupila con su haz de luz que ha viajado hasta aquí. Y, en medio, una formación espacio-temporal difícilmente concebible, excepto que recurramos a la teoría del holograma. 
La imagen astronómica detiene el proceso pero me muestra su ambigüedad, una de tantas: veo la galaxia de Andrómeda como era hace dos millones y medio de años, y a la vez reconozco que esa configuración que ha impresionado la placa fotográfica corresponde a un referente que se halla en el origen de ese rayo de luz, a miles de millones de kilómetros de distancia, ahora mismo.

En 1992 una imagen insólita apareció en todos los periódicos del mundo. Era, según decía la noticia, una instantánea del universo en el momento en que empezó a existir el espacio. Pero como siempre, la imagen científica encerraba una incongruencia. Se trataba de una imagen compleja, mezcla de realidad e imaginación: nadie estaba preparado, entre el público en general, para "comprender la paradoja de una imagen que representa simultáneamente una visión desde la tierra hacia el exterior en todas las direcciones y una visión hacia nuestro planeta en todas las direcciones que confluyen en el big bang" (Osserman, 1997, p. 10). Ciertamente, el planteamiento no se antoja fácil de entender, aunque su paradoja es la misma que hemos descubierto al contemplar la imagen de la galaxia de Andrómeda. Es más, la paradoja aparece siempre que observamos el cosmos. Nuestra vista se lanza hacia el exterior en todas direcciones, pero a la vez la luz viene hacia ella de todas las direcciones: el presente de mi visión se ve penetrado por el pasado del cosmos y viceversa.

En la fotografía esta contradicción de la que está hecha la realidad cósmica, equivalente a la que aparece cuando se intuye la realidad atómica y subatómica, se complica en el momento en que se interpone la técnica fotográfica. Una imagen de este tipo no puede ser tomada como una instantánea: el tiempo en ella se desarrolla también físicamente, puesto que es necesario un período de exposición para que la imagen quede registrada tal como la vemos, en todo su detalle. La fotografía muestra el tiempo, a la par que lo acumula.

\section{LAS NO IMÁGENES}

Latour ya indicaba que la imagen científica es un objeto dinámico cuyo significado se adquiere mediante su tránsito de una referencia a otra: "Una imagen científica aislada, estrictamente hablando, no tiene referente [...] La referencia es un movimiento, una deambulación, una trayectoria, no una propiedad de una imagen 'realista'"' (Latour, 2014, p. 359). El sociólogo se refiere al hecho de que una imagen científica debe ser interpretada a partir de determinados pará- metros que han sido delimitados en otro ámbito científico, y a que el resultado de una interpretación sirve de referencia para un planteamiento posterior. En otro momento, Latour había examinado el fenómeno de lo que denominaba los "móviles inmutables", cuyo ejemplo más característico eran las imágenes realizadas por los dibujantes que acompañaban a los primeros exploradores del Nuevo Mundo: en sus dibujos fijaban una realidad que luego se movía, circulaba por las redes de conocimiento de la metrópoli. La definición que Latour hace de la información se parece extrañamente a las consideraciones de Barthes sobre la fotografía: "La información no es un signo, sino una relación establecida entre dos lugares, el primero convertido en periferia y el segundo en centro, que se da con la condición de que entre los dos circule un vehículo, al que se suele llamar forma pero que, para insistir en su aspecto material, yo llamo inscripción" (Latour, 1999, p. 162).

La imagen científica aparece como un ente misterioso en la historia de la representación. Pretende ser una apuesta radical por la realidad que irrumpe en el siglo XVII en el ya antiguo territorio de la imagen, produciendo en el mismo un agujero que lo atraviesa de arriba a abajo y va a dar a otra parte que es en gran medida inusitada. Todo ello sin abandonar totalmente las características propias de la visualización tradicional, lo que podríamos denominar su "vestimenta". Se trata de otra imagen o, parafraseando con toda intención a Foucault, de una imagen otra, insertada dentro del campo de la visualización tradicional con la que a veces ingenuamente se confunde.

¿Por qué resulta pertinente considerar que la imagen científica es una "imagen otra", equiparable a un no-lugar? Entre las cosas que determinan igualmente su otredad debemos considerar el hecho de que es una imagen de tránsito, donde el científico no habita y con la que no se compromete más que un instante. Guarda con la metáfora, a la que la ciencia aborrece, esa característica que le adjudican las mentes literales y por la que debe autodestruirse en el mismo instante en que es creada. Una paradoja más, pues: el científico está rodeado de imágenes, trabaja todo el tiempo con imágenes mentales, virtuales, reales o técnicas, pero en el fondo pretende ignorarlas. Las deja para el profano.

Pero esto solo tiene sentido si consideramos la imagen científica como perteneciente al ámbito de la representación: en tal caso el compromiso del científico con la misma es muy liviano y el científico solo lo admite si desea cometer el pecado de divulgación. Hei- 
senberg y Schrödinger mantuvieron durante los años veinte del pasado siglo una famosa polémica sobre la visualización en la ciencia: Heisenberg se mostraba contrario a la misma porque consideraba, entre otras razones, que visualizar los procesos constreñía la posibilidad de descubrir nuevos fenómenos al circunscribir cualquier fenomenología al modelo visual vigente. Repitiendo el postulado de Galileo, manifestaba que la nueva teoría cuántica "debía liberarse de las imágenes intuitivas y utilizar solo cantidades mesurables" (Miller, 1987, p. 148). Por el contrario, Schrödinger entendía que era "extremadamente difícil imaginar procesos tales como los fenómenos de colisión mediante una teoría del conocimiento en la que se suprime la intuición y se opera solo con conceptos abstractos tales como las posibilidades de transmisión, niveles de energía y cosas parecidas" (Miller, 1987, p. 143).

Cuando se confronta a los escépticos de la visualización con las paradojas que produce la mecánica cuántica acostumbran a decir que solo se está hablando de operaciones matemáticas. Pero esta afirmación conlleva una inevitable incoherencia, ya que una de dos: o esas operaciones se refieren a alguna propiedad de lo real por recóndita que pueda ser, o bien son pura metafísica. En cualquier caso, las formulaciones producen al parecer resultados experimentales, indican obviamente alguna propiedad del mundo físico, el cual pasa entonces a comportarse de la manera incongruente revelada por los denostados divulgadores de la teoría.

La cuestión es de qué manera se ha de poder visualizar esta fenomenología. No cabe duda de que las paradojas visuales que se desprenden de la misma, y que artistas como Escher han representado a su manera, tienen, de entrada, el valor alegórico del que hablaba antes. Las imágenes del mundo cuántico, científicas o no, funcionan como alegorías. Y no olvidemos que la alegoría es una forma de pensar.

Pero quienes pretenden que la visión humana es tan absoluta que puede relacionarse con la realidad a todos los niveles, de la misma manera que la concepción newtoniana de las leyes físicas consideraba que estas eran universales, pueden caer en un fácil error. Un ejemplo lo tenemos en el célebre film didáctico Powers of Ten elaborado por la pareja de diseñadores norteamericanos Charles y Ray Eames en los años setenta del pasado siglo. En él se narra visualmente un viaje por el cosmos, hacia lo más grande y hacia lo más pequeño, a partir de un punto central, una pareja que está haciendo picnic en un parque. Arrancando de este encuadre, la cámara inicia un zoom que, ale- jándose a una velocidad basada en factores de diez que aumentan cada segundo (10 metros, 100 metros, 1000 metros), llega hasta los confines del universo, allí donde ya no hay materia. Luego regresa y, al alcanzar de nuevo la escala humana, atraviesa la piel del cuerpo del hombre y, a la misma velocidad, penetra en su interior hasta llegar a contemplar las partículas elementales, tras las cuales se encuentra también la ausencia de materia, el vacío. La hipótesis clásica del hombre en cuanto medida de todas las cosas, así como la del cuerpo en tanto interfaz entre el cosmos y el microcosmos, se hallan presentes en el proyecto.

Nos enfrentamos a dos ideas contradictorias. Por un lado, la propuesta de un mundo, de una realidad humana, fuera de la cual nada es concebible: como decía Wittgenstein, de lo que no se puede hablar hay que callar. Por otro, la pretensión de que el universo es homogéneo de uno a otro confín y de que, en consecuencia, como quería Schrödinger, todo es visualizable en la misma medida naturalista. No se trata solo de que el planteamiento del vídeo contradiga el postulado de la velocidad insuperable de la luz, sino de que considera que traspasar esa barrera no implica ningún cambio en la visión de la realidad, lo cual es inconcebible, puesto que, presuntamente, la visión del universo ha de desaparecer en el momento en que los ojos corran más rápido que la luz que produce la visibilidad del mismo. Es igualmente ingenuo pensar que si la visión, la cámara, alcanza magnitudes infinitesimales al introducirse en el cuerpo y luego llegar al átomo, conservará todas sus propiedades mecánicas. Allí el ojo o la cámara que lo representa se habrán diluido también en las partículas atómicas que forman la materia de la que están compuestos.

El film de los Eames nos muestra literalmente un alejamiento del cuerpo a la par que un intento de acercamiento a lo real. Zizek insiste en El acoso de las fantasías en que aproximarse extremadamente al objeto produce horror, el horror de lo real que solo puede paliarse con una dosis de fantasía: "Podemos ver claramente cómo la fantasía está del lado de la realidad, cómo soporta el 'sentido de realidad' del sujeto: cuando el marco fantasmático se desintegra el sujeto sufre una 'pérdida de realidad' y comienza a percibir la realidad como un universo 'irreal' pesadillesco, sin una base ontológica firme: este universo pesadillesco no es 'una mera fantasía' sino, por el contrario, lo que queda de la realidad cuando esta pierde su apoyo en la fantasía" (Zizek, 1999, p. 31).

Lo que alegoriza la propuesta de los Eames es, pues, la contradicción entre el universo humanis- 
ta y el universo científico. Si el universo humanista resguarda los fenómenos e incluso permite que el mito, a diversos niveles de enunciación, dé sentido a la realidad, el universo científico pretende alcanzar el núcleo básico de lo real pero a costa del significado y de la visión. Para ello se apoya en otra mitología, contraría a la anterior: si la una pretende preservar la escala humana a toda costa, la otra la descompone, también sin miramientos.

Hubo un tiempo en que esto no fue así, un tiempo en que la imagen era atesorada como testimonio de aquello que no se podía ver directamente, pero que era necesario tener ante la vista. Se trata de la gran época de las ilustraciones de la zoología y la botánica. Se producía en ese momento, en los siglos XVII y XVIII, un equilibrio entre las dos tensiones, la humanista y la científica, puesto que tales ilustraciones estaban hechas a escala humana pero al mismo tiempo pretendían ajustarse a una necesaria objetividad científica, la cual implicaba que vinieran desprovistas de cualquier referencia a un lugar y a un momento concretos. Si bien se eliminaba de ellas científicamente la contingencia, aparecía por otro lado la estética para acompañarlas en su aliento humanista, a veces de manera tremendamente exuberante.

¿Qué tipo de imagen precisa la nueva ciencia, que sea capaz de integrar los distintos factores en litigio para que el objeto se vuelva asimilable a la escala humana sin perder las características que le son propias y para que, al mismo tiempo, las funciones del sujeto en la visión y comprensión de ese objeto sean convenientemente representadas? No cabe duda de que necesitamos un nuevo tipo de planteamiento visual, una visualización correspondiente a la mencionada tercera cultura.

\section{HUMANO, DEMASIADO HUMANO}

En los más de ochenta paneles que componen el Atlas Mnemosyne de Warburg, que en su conjunto recoge alrededor de un millar de imágenes, solo hay tres que puedan considerarse genuinas imágenes científicas. Dos de ellas se refieren a Kepler y la otra representa "las órbitas planetarias según el concepto moderno". De las dos de Kepler, una traza "la órbita de Marte según las observaciones (de este astrónomo)", y la otra, que es de las tres la más famosa, corresponde a la "identificación de las órbitas planetarias con los sólidos regulares" tal como aparece en Mysterium cosmopraphicum, una obra de 1621. Todas estas imágenes se encuentran en un solo panel, el C, cuyo epígrafe introductorio indica que en él se resu- me la "evolución de las ideas sobre Marte", así como la "superación de la concepción antropomórfica de la imagen" (Warburg, 2010, p. 12).

Sin embargo, en el mismo Atlas, Warburg incluye numerosas imágenes relacionadas con la astrología. Parece como si con ella se agotara la concepción antropomórfica de la imagen a la que hace referencia el encabezamiento del panel, aquella de la que se dice que está siendo superada. Cabría suponer que el trueque se realiza con la geometría, a juzgar por el tipo de imágenes que Warburg coloca en ese panel. Pero la geometría, especialmente representada por el círculo o la esfera, también había estado presente en las imágenes anteriores, claramente antropomórficas.

El antropomorfismo al que alude Warburg no viene dado por el hecho de que la figura humana esté presente en las representaciones, sino porque estas se ajustan en principio a las coordenadas que trazan el cuerpo y la visión, son hechas por y para ellas. Por el contrario, las nuevas imágenes científicas se instalan en un no-lugar que ya no dependen de esos parámetros: son un no-lugar situado en otro no-lugar. $\mathrm{O}$ eso creen o pretenden los científicos que las utilizan, si bien están lejos de interpretarlas de esta manera e incluso de imaginar que puedan ser así interpretadas. La frase que Marx atribuye a la economía política de la burguesía podría igualmente aplicarse a una ciencia no menos burguesa: no lo saben pero lo hacen.

El punto de inflexión entre la ciencia antigua y la ciencia moderna, entre la visión humanista del mundo y la científica, se sitúa en una célebre controversia que mantuvieron Kepler y Robert Fludd a principios del siglo XVII. Se enfrentaban, en ese momento, dos mentalidades, y lo hacían a través de la ontología de las imágenes. Kepler encarnaba la facción que saldría vencedora y para la que las imágenes en la ciencia solo podían representar el mundo físico. Fludd, por el contrario, acarreaba consigo las formas del neoplatonismo y consideraba que este mundo físico no era más que la sombra de las ideas, unas ideas metafísicas que eran las que debían ser visualizadas.

Pero Kepler no estaba completamente exento de la influencia de cierta metafísica, ni su tendencia a reducir la visualización a las formas geométricas le apartaba de un uso heurístico de la geometría no tan alejado como él quería de los procedimientos de Fludd.

Kepler descubrió sus leyes sobre las órbitas planetarias a través de las imágenes. Fue un proceso de pensamiento visual lo que lo llevó a las formulas matemáticas correspondientes: 
Durante una de sus clases sobre geometría se puso a dibujar un triángulo equilátero. En su interior dibujó un círculo de manera que tocara los tres lados del mismo, y alrededor del triángulo trazó otro círculo que tocaba sus vértices, tal como lo había descrito Pitágoras. De pronto, todo cobró sentido. Se trataba de un modelo del universo (Miller, 2009, s. p).

Tal procedimiento, de raíces claramente pitagóricas, lo condujo a dar el primer paso hacia el cálculo de la relación entre las órbitas de los seis planetas conocidos: "El resto de la inspiración llegó como un flash. Saturno y Júpiter son los 'primeros' planetas (es decir, los más alejados) y el triángulo es la primera figura de la geometría. Inmediatamente, inserté (es Kepler quien habla) en el siguiente intervalo entre Júpiter y Marte un cuadrado, entre Marte y la Tierra un pentágono, entre la Tierra y Venus un hexágono..." (Koestler, 1963, p. 149). Pero este primer intento no fue válido. Solo cuando decidió cambiar las figuras bidimensionales por las tridimensionales equivalentes llegó a la conclusión adecuada. La nueva intuición fue impulsada por el hecho de que a los poliedros regulares se los denomina "sólidos platónicos" o "pitagóricos" por su perfección. No existen más que cinco de ellos que tengan todas las caras iguales: cinco, como los planetas conocidos en ese momento. Recordemos que Kepler había aceptado la revolución copernicana que desplaza a la tierra como centro del universo para colocar en su lugar al sol porque, como afirmaba Pauli, "contemplaba el sol y el resto de planetas a partir de una idea arquetípica [...] Eran sus creencias religiosas las que le impulsaban a buscar las verdaderas leyes del movimiento planetario" (Miller, 2009, s. p).

A pesar de su herencia pitagórica y de las operaciones alegóricas que organizaban su pensamiento, cuando Kepler se encontró con el libro ampliamente ilustrado de un personaje tan enigmático como Robert Fludd, que también pretendía comprender el universo mediante imágenes, no dudó en criticarlo abiertamente. Los unía el uso del pensamiento visual, pero los separaba un mundo de conceptos.

La polémica que se desarrolló entre ellos pone de manifiesto dos maneras absolutamente distintas de entender las imágenes y su valor epistemológico. Kepler consideraba que Fludd se dejaba llevar por imágenes hechas de aire, sin fundamento, y este argüía contra Kepler que "el alma no llega a conocer mediante 'numeraciones', dividiendo las cosas en partes, sino buscando unidades en la multiplicidad de las oscuras, ocultas experiencias, y lo hace creando imágenes de unidad" (Westman, 1986, pp. 199-200).
Kepler convierte las ideas religioso-científicas en figuras geométricas que son a la vez formas de la cantidad y formas de la racionalidad, además de arquetipos, como las consideraba Pauli. Fludd, por el contrario, pretendía representar el funcionamiento del mundo sin mediaciones: sus imágenes eran como discursos explicativos de un trabajo oculto de carácter místico, pero sus raíces arquetípicas eran igualmente significativas. Kepler estimaba que las imágenes de Fludd eran poéticas, ya que respondían a la definición que Aristóteles hace de la metáfora en su Poética. Sin embargo, a la pregunta por cómo podemos estar seguros de que nuestras imaginaciones visuales no son sueños, poesía o retórica, la respuesta de Kepler era que "la capacidad imaginativa del alma es de un tipo particular denominado symbolisatio. Symbolisatio es una actividad por medio de la cual el alma equipara lo sensible con lo inteligible coeterno, con Dios" (Westman, 1986, pp. 204-205). Con todo, ¿qué es en realidad este proceso de simbolización sino una adecuación a los arquetipos, por ejemplo al de la esfera-dios?

Para Kepler, según Westman, "los poliedros son formas matemáticas que existen independientemente de la materia, pero que definen las relaciones de distancia entre los planetas. Al mismo tiempo, los poliedros participan de la inteligibilidad divina y sus designios". Fludd afirmaba, por el contrario, que "en lugar de palabras geométricas, usaba palabras físicas. Atribuyo mi armonía del mundo natural a formas que corresponden a acciones que están escondidas en la materia" (Westman, 1986, p. 207). No sé hasta qué punto debemos considerar que estos dos mundos están tan alejados, si tenemos en cuenta lo que decía Richard Feynman acerca del electrón: “El electrón es una teoría que usamos, es tan útil para comprender cómo funciona la naturaleza que casi podemos calificarlo de real" (Feynman, 1985, p. 70).

Es conocido el interés que Wolfgang Pauli, premio Nobel de Física, demostró por la idea de Jung sobre los arquetipos. Ello lo llevó a ocuparse también intensamente de la antigua controversia entre Fludd y Kepler. En su escrito La interpretación de la naturaleza de la psique analiza las raíces metafísicas del pensamiento del astrónomo y las contrasta con la argumentación visual, aún más drásticamente metafísica, que efectúa Fludd a través de una serie de imágenes tan sorprendentes entonces como lo son ahora. Su conclusión es que "los esquemas físicos y psíquicos muestran no tanto oposiciones como aspectos complementarios de una misma realidad" (Westman, 1986, p. 212). 
Si regresamos ahora imaginariamente al punto donde se escindieron esas dos visualidades, dependiente cada una de ellas de su correspondiente imaginario, podemos vislumbrar la posibilidad de suturar semejante partición que no es otra cosa que una herida abierta en la mente occidental.

Esta brecha, reeditada aún más drásticamente en el siglo pasado por las controversias de la física cuántica acerca de la visualización, nos muestra que en el seno de tal forma científica se produce un cisma entre lo que se dice y lo que se hace: la acción es puramente matemática, sin significado, y el significado, por su parte, está irremisiblemente abocado a la fantasía, fundamentada en los procesos de visualización. Quizá debería haberse prestado mayor atención a la coincidencia en el tiempo entre la consolidación de las ideas de la mecánica cuántica y el surgimiento del surrealismo. Una correspondencia que solo fue percibida, creo, por Dalí, aunque ello no ocurrió hasta los años cuarenta del pasado siglo, cuando la fuerza del surrealismo ya estaba en declive. Sin embargo, al contemplar ahora las visualizaciones que se efectúan de los "grandes datos", nos vienen a la memoria no solo las formas surrealistas, sino también los antecedentes de las mismas que hay en las imágenes de Fludd.

La ciencia quiere referirse a lo real, sin tener en cuenta la realidad. Pero las imágenes son siempre una respuesta a la realidad desde la imaginación. Observamos ahora que los procedimientos científicos, que son diferentes del idealismo del método científico, se acercan en gran medida a los artísticos, gracias sobre todo a la intervención de la tecnología en los dos ámbitos. Es por ahí por donde puede detectarse la posibilidad de una ciencia poética, capaz de ser científica sin olvidarse de ser humana.

\section{BIBLIOGRAFÍA}

Barthes, R. (1997). La cámara lúcida. Barcelona: Paidós.

Coopmans, C., Vertesi, J., Lynch, M. y Woolgar, S. (eds.) (2014). Representation in Scientific Practice Revisited. CambridgeMassachusetts: The MIT Press, pp. 1-12.

Deleuze, G. (2013). El saber. Cursos sobre Foucault (tomo I). Buenos Aires: Editorial Cactus.

Feynman, R. (1985). Surely, you're joking, Mr. Feynman. Adventures of a Curious Character. New York: W.W. Norton \& Company.

Flusser, V. (2006). Towards a Philosophy of Photography. London: Reaktion Books.

Freedberg, D. (2002). The Eye of the Lynx. Galileo, his Friends, and the Beginning of Modern Natural History. Chicago: The University of Chicago Press. https://doi.org/10.7208/chicago/9780226261539.001.0001

Frigg, R. y Hunter, M. C. (eds.) (2010). Beyond Mimesis and Convention. Representation in Art and Science. London: Springer. https://doi.org/10.1007/97890-481-3851-7

Jay, M. (2007). Ojos abatidos. La denigración de la visión en el pensamiento francés del siglo XX. Madrid: Akal.

Koestler, A. (1963). The Sleepwalkers. New York: Grosset \& Dunlap.
Latour, B. (1999). Las redes que la razón ignora: laboratorios, bibliotecas, colecciones. En: García Selgas, F. J. y Monleón, J. B. (eds.) Retos de la posmodernidad. Madrid: Trotta, pp. 161-183.

Latour, B. (2001). La esperanza de Pandora. Ensayos sobre la realidad de los estudios científicos. Barcelona: Gedisa.

Latour, B. (2014). The More Manipulations the Better. En: Coopmans, C., Vertesi, J., Lynch, M. y Woolgar, S. (eds.) Representation in Scientific Practice Revisited. CambridgeMassachusetts: The MIT Press, pp. 78-103. https://doi.org/10.7551/mitpress/9780262525381.003.0022

Milburn, C. (2008). Nanovision. Engineering the future. Durham: Duke University Press.

Miller, A. I. (1987). Imagery in Scientific Thought. Creating Twenty Century Physics. Cambridge-Massachusetts: The MIT Press.

Miller, A. I. (2009). Jung, Pauli, and the Pursuit of a Scientific Obsession. New York: W. W. Norton \& Company.

Moser, S. (1996). Visual Representation in Archeology: Depicting the Missing-Link in Human Origins. En: Bagigrie, B. S. (ed.) Picturing Knowledge. Historical and Philosophical Problems Concerning the Use of Art in Science. Toronto: University of
Toronto Press, pp. 184-214. https://doi. org/10.3138/9781442678477-008

Osserman, R. (1997). La poesía del universo. Una exploración matemática del cosmos. Barcelona: Grijalbo.

Sonda, G. (2010). VISION: the Art of Manifesting the Invisible. En: 28th Standing Conference on Organizational Symbolism SCOS 2010. 7 al 10 de julio de 2010, Lille, Fracia. Lille: Universidad de Lille.

Talbot, M. (1992). The Holographic Universe. New York: Harper Perennial.

Vertesi, J. (2014). Drawing as: Distinctions and Disambiguation in Digital Images of Mars. En: Coopmans, C., Vertesi, J., Lynch, M. y Woolgar, S. Representation in Scientific Practice Revisited. Cambridge-Massachusetts: The MIT Press, pp. 15-35. https://doi.org/10.7551/mitpress/9780262525381.003.0002

Vickers, B. (ed.). Occult and Scientific Mentalities in the Renaissance. Cambridge: Cambridge University Press, pp. 177-229.

Warburg, A. (2010). Atlas Mnemosyne. Madrid: Akal.

Westman, R. S. (1986). Nature, Art, and Psyche: Jung Pauli, and the Kepler-Fludd polemic. En: Zizek, S. (1999). El acoso de las fantasías. México: Siglo XXI. 